\title{
RORTY'S THESIS OF THE CULTURAL SPECIFICITY OF PHILOSOPHY
}

\begin{abstract}
In his brief consideration of non-Western philosophy between 1989 and 1991, Richard Rorty argued that dialogue between Western philosophy and non-Western traditions is not constructive since it almost inevitably involves fundamental misunderstanding, and he even expressed doubt about whether non-Western philosophy exists. This reaction seems out of character, given that Rorty specialised in forging unlikely alliances between philosophers from different Western traditions, and was an enthusiastic advocate of edification through hermeneutic engagement with unfamiliar vocabularies. I argue that given Rorty's conception of philosophy as a literary tradition, he had no reason to exclude non-Western figures, and that his various arguments against the desirability of comparative philosophy - based on the different purposes of different traditions, their different conceptual schemes, and his notion of 'transcultural character' - are all inconsistent with more characteristic elements of his thought, as well as independently unconvincing. The underlying reason Rorty adopted this combative stance towards comparative philosophy, I argue, is that non-Western philosophy undermines his critique of Western philosophy, which depends on a cultural specificity thesis according to which philosophical problems are rooted in obsolete European social needs. Against this thesis, I conclude by arguing that philosophy has a natural subject-matter.
\end{abstract}


On the face of it, it is easy to imagine Richard Rorty as an enthusiastic advocate of cultural exchange with non-Western philosophy, given the potential this offers for expanding intellectual horizons and escaping what Rorty regarded as the parochialism of contemporary Western philosophy. After all, he had famously little respect for the boundary between the analytic and continental philosophy traditions, with his free and unselfconscious use of Heidegger's ideas, in particular, being a major factor in helping them gain respectability within Anglo-American philosophy (Guignon 1986: 401). Perhaps Rorty’s most prominent announcement of his disregard for philosophical boundaries came at the beginning of Philosophy and the Mirror of Nature, where he listed his main influences as Dewey, Heidegger and Wittgenstein, and then lumped them together as 'therapeutic' philosophers who 'set aside' rather than 'argue against' traditional epistemology and metaphysics (Rorty 1979: 5-7). Despite the apparent gulf between these figures, then, Rorty had no qualms about attributing a common message to them, with his instinctive eclecticism backed up by the metaphilosophical claim that, "the difference between "analytic" and other sorts of philosophy is relatively unimportant - a matter of style and tradition rather than a difference of "method" or of first principles' (ibid.: 8). You might have expected him to say the same of non-Western philosophy.

Given that Rorty was renowned for his ecumenical approach, then, and specialised in finding unlikely affinities, piecing ideas together with his self-professed 'talent for bricolage' (Knobe 1995), he seems exactly the kind of philosopher who would want to include non-Western philosophers among the already myriad points of reference within his works. Moreover the philosophical ideas of Zhuangzi, the Samkhya school, and Dōgen, for instance, all seem 
rather more natural choices than the novelists and poets who did, from the mid-' 80 s onwards, become central to his work. But quite apart from the circumstantial evidence of Rorty's reputation for open-mindedness and readiness to step outside the analytic fold, the most compelling reason to think that Rorty would embrace non-Western philosophy is to be found at the very heart of his thinking.

After attempting to historically deconstruct and thereby undermine the representationalism and foundationalism of post-Kantian Western philosophy in Philosophy and the Mirror of Nature, Rorty ended his book with the positive proposal that epistemology and the search for knowledge be replaced by hermeneutics and the search for edification, where edification is conceived as a project of self-creation and unceasing development, accomplished by finding ever new and more useful ways to describe ourselves, others, and the world around us. ${ }^{1}$ Unlike the epistemological search for the objective truth, Rorty conceived the project of edification as having no terminating point, being rather an 'infinite striving' for new descriptions which incorporate new points of view (Rorty 1979: 377); he accorded the highest significance to this project, holding that 'redescribing ourselves is the most important thing we can do' (ibid.: 358-9). Thus while epistemology-centred philosophy, according to Rorty, sought universal commensuration through the development of an abstract matrix of sensations and concepts with which to render all discourses commensurate, thereby allowing their truth to be algorithmically adjudicated, Rorty's alternative of edification, by contrast, requires us to actively seek out and engage with incommensurable vocabularies.

The value of edifying engagement with incommensurable vocabularies, for Rorty, is that it prevents culture from freezing over with intellectual complacency when old vocabularies become so entrenched as to be practically unquestionable; it thereby expands our descriptive 
capabilities, promoting open-mindedness and tolerance as we look beyond our own discourses. There are two main ways for edification to proceed. One is the 'poetic' activity of devising new incommensurable discourses (ibid.: 360); for this we can only wait and hope for new original thinkers to emerge. And the other is by hermeneutically engaging with discourses employed by different academic disciplines, different cultures, different historical periods, or any combination thereof; Rorty even thinks that imagining other cultures, such as the extra-terrestrial 'Antipodeans' of his well-known thought-experiment (ibid.: 70 \& ff.), can promote edification. This commitment to engaging unfamiliar discourses strongly suggests that Rorty would consider hermeneutic engagement with non-Western philosophy a paradigmatic project of edification. Moreover, it seems a project peculiarly suited to his needs, given that like Dewey before him, Rorty wanted to demonstrate the historical contingency and hence dispensability of the traditional problems of Western philosophy; Rorty invented the 'Antipodeans' to help us imagine a culture free of the influence of Plato and Kant, but this seems unnecessary when he could have appealed to non-Western philosophy instead. Bringing non-Western ideas to the attention of Western philosophers, then, seems like an obvious source of Rortyan edification, as well as an equally obvious method for showing the contingency of deep-rooted presuppositions in Western philosophy, especially given that comparative philosophy has often served this latter purpose exactly. ${ }^{2}$

Rorty's substitution of edification for epistemology was intended to promote a conception of 'culture as a conversation rather than as a structure erected upon foundations' (ibid.: 319), and he imagined the role of the philosopher in this new kind of culture as,

the informed dilettante, the polypragmatic, Socratic intermediary between various discourses. In his salon, so to speak, hermetic thinkers are charmed out of their self- 
enclosed practices. Disagreements between disciplines and discourses are compromised or transcended in the course of the conversation. (ibid.: 317 )

Given the central importance he placed in dialogue between independent discourses, then, it does seem frankly amazing that in his few explicit statements on dialogue with non-Western philosophy (Rorty 1989, Rorty 1991, Balslev 1991), Rorty’s attitude was almost entirely dismissive. He seemed sure such conversation could not be useful, thought it would almost inevitably involve fundamental misunderstanding, and even went so far as to wonder whether non-Western philosophy exists, saying he found it 'perfectly reasonable to ask, without condescension and in honest bewilderment, the question (...): 'Is There Philosophy in Asia?' (Rorty 1989: 333). ${ }^{3}$

What brought Rorty around to this apparently anomalous view? The underlying reason, I shall be arguing, is that non-Western philosophy presents the most glaring counterexample possible to a thesis which is central to Rorty's critique of philosophy, and hence to his thought as a whole, namely his thesis of the cultural specificity of philosophy. To defend this thesis required him to reject any extension of the philosophical 'conversation' beyond the Western world, despite the fact that this rejection was at odds with many other aspects of his thinking. The cultural specificity thesis is false, however, which is one of the main overall problems with Rorty's case for pragmatism. ${ }^{4}$ This paper will continue as follows. In the next two sections I consider and reject Rorty's various reasons for disparaging dialogue with nonWestern philosophy. Then in section IV, I sketch an alternative to the cultural specificity thesis, according to which it is no more surprising that different cultures have independently developed philosophy, than that they have independently developed mathematics or astronomy. 
Philosophy is often thought of as dealing with perennial problems that might occur to anybody, at any time or within any culture, if they were to reflect in the right way. Compared to social or political problems raised by particular circumstances, such as the invention of new technologies or the recent actions of a foreign power, questions about the nature of knowledge, mind, substance and time seem as acultural and ahistorical as questions about how rivers are formed, how the planetary motions are organised, or how microorganisms reproduce. Familiarity with intellectual history, however, reveals that this familiar picture cannot be quite right, since philosophical problems that now seem intuitively obvious to us, have been shaped by innumerable theoretical developments over the course of history, and even the concepts we employ are to some extent historical products. Thus as Wallace Matson argued, in a paper Rorty makes central to his attempted historical deconstruction of the concept of mind (Rorty 1979: 46 \& ff.), although the question of how sensations relate to brain states is a central concern for contemporary philosophers, the ancient Greeks recognised no such problem, not because they overlooked something obvious (they were 'not the dullest people who ever lived', Matson notes (Matson 1966: 95)), but because their concept of mind centred on intellect rather than sensation. It was only after Descartes that sensations became paradigmatic of mind, allowing the mind-body problem as we know it to emerge. Given that the Western concept of mind has undergone many other changes over its long history (see Macdonald 2003), and there is no reason to consider it unique among philosophical concepts, Matson's thesis, if accepted, suggests that the traditional problems of philosophy may be rather less perennial and more historically conditioned than we might at first have supposed. 
However it is one thing to hold that the way we frame philosophical problems is historically conditioned, such that different generations of philosophers have approached different philosophically puzzling phenomena, such as the fact that time passes or that human beings perceive and think about the world, in different, even radically different, ways. But it is quite another to hold that there are no philosophically puzzling phenomena in the world, and that the very idea of a 'philosophical problem' is instead rooted in historically specific social conditions that might never have arisen. The latter is Rorty's view. He does not deny manifest facts such as that time passes or that human beings perceive and think, of course, but rather that there is anything intrinsically puzzling about these phenomena of a kind which generates distinctively philosophical problems. Rather they are phenomena that were alighted upon because of their perceived relevance to a social need once felt within a particular culture, and subsequently problematized in a way that came to be regarded as philosophical. Thus Rorty denies that philosophy has any natural subject-matter, in the way that other disciplines such as astronomy and physics do. Rather it a thoroughly contingent conversation which began in an attempt to meet specific social needs. Moreover Rorty thinks that these social needs have long-since become obsolete; this jars with his pragmatism, and provides the instinctive basis of his opposition to the philosophical tradition. Dewey's opposition to the tradition was much the same: he wanted American philosophy to break from its European past to deal with issues relevant to contemporary life, rather than remain 'an ingenious dialectic exercised in professorial corners by a few who have retained ancient premises while rejecting their application to the conduct of life' (Dewey 1917: 58).

This radically historicist conception of philosophical problems is made concrete in Rorty's attempt to deconstruct Western philosophy. Central to this deconstruction are what Michael 
Williams has called Rorty's 'emergence' and 'projection' theses (Williams 2000). Thus according to Rorty (1979: chapters 1 and 3), philosophy first became a distinct academic pursuit in the seventeenth century, when Descartes set out to provide foundations for knowledge that would be capable of supporting the newly emerging mathematical sciences in their struggle for hegemony against church doctrine; this is the emergence thesis. This project was made possible by Descartes' 'invention' of the representational mind, which he achieved by literalising the pre-existing metaphor of the mind as a mirror of nature, and thereby transforming the concept of mind into the concept of a subjective arena in which the objective world is represented. Kant then entrenched the idea of philosophy as an a priori study of how our minds represent the world by drawing the analytic / synthetic and intuition / concepts distinctions, and tying these distinctions in with continuities in intellectual history, most notably traditional concerns about universals and particulars, which allowed nineteenth century historians to project Kant's concerns back in time in order to construct a standard history of philosophy that stretched from ancient Greece to the present; this is the projection thesis.

Thus rather than philosophy being an ancient subject dealing with perennial and inevitable problems for the human intellect, in Rorty's story it turns out to be a modern project that arose in response to a specific social concern, namely the tension within the European enlightenment between science and religion. Moreover, Rorty thinks the Greek idea of the mind as distinctive for its ability to know universals, an idea he says Descartes and Kant needed to draw upon in order to originate representational epistemology, and thus effectively philosophy itself, was also a product of a particular social need, namely the need to find some feature which raises human beings above the level of animals and thereby account for their dignity. The distinctively Greek response to this need was that 'the crucial difference between 
men and beasts is that we can know - that we can know not merely singular facts but universal truths' (Rorty 1979: 35), with it being our possession of the special ingredient of mind that grants this ability. According to Rorty, then, philosophy is the result of two thoroughly contingent responses to social needs that arose in European culture at significant historical junctures. These responses generated a literature, and in an oft-cited passage, Rorty claimed that philosophy was nothing more than this resultant literary tradition:

All that 'philosophy' as a name for a sector of culture means is 'talk about Plato, Augustine, Descartes, Kant, Hegel, Frege, Russell ... and that lot.' Philosophy is best seen as a kind of writing. It is delimited, as is any literary genre, not by form or matter, but by tradition ... (Rorty 1982a: 92)

Rorty later retracted part of this by denying that philosophy is even so much as a 'literary genre', on the grounds that “"genre” suggests format' (Balslev 1991: 61). Rather, all he had ever meant to claim, he now said, was that philosophy is 'a genealogical linkage connecting certain past figures with certain present figures (...) an ancestoral relation of overlapping fibers' (ibid.). Thus if we piece Rorty's claims together, his considered view seems to be that philosophy has no distinctive subject-matter or methodology, and is not even a genre of literature, since it involves no distinctive literary format. Rather it is a literary tradition we recognise by the names that appear in the text, with those names ultimately referring back to figures like Plato and Descartes, who instigated attempts, now known to be misguided, to address social issues which were felt in their time, but which are now thoroughly obsolete.

This account suggests that philosophy is an essentially European phenomenon: it is a European literary tradition that arose in response to particular European social needs. If this is 
right, then the reason for Rorty's scepticism about the value of comparative philosophy might seem obvious enough, namely that there is, by definition, no non-Western philosophy to compare. However this would be an impossible position for Rorty to maintain, given that he was an anti-essentialist par excellence; it was against the idea that certain descriptions have a privileged attachment to reality itself, on account of accurately representing essences, that Rorty proposed his alternative of edification and endless redescription, restrained only by imagination and social usefulness. Given this extreme liberalness about how we employ descriptions, then, it seems Rorty is not in a position to hold that there is a principled reason, due to the essentially European nature of philosophical inquiry, why we should not describe non-Western figures as 'philosophers'.

Moreover, Rorty's fluid conception of philosophy as a literary conversation seems entirely conducive to expanding the list of figures that need to be mentioned if a work is to count as philosophical, especially given that throughout the twentieth century, non-Western philosophers have increasingly been mentioned in the same breath as 'Plato, Augustine ... and that lot'. There is even evidence that non-Western thinkers entered this conversation considerably earlier, at about the time Rorty thinks Kant was effectively inventing a new discipline called 'philosophy', since Leibniz was thoroughly versed in Chinese thought (Clarke 1997: 46-8), and there is a possibility that Hume was influenced by Buddhism (ibid.: 127; Jacobson 1969; Gopnik 2009); these philosophers were of course definitive influences on Kant. And in any case, the influence was fully in place by the time of Schopenhauer and Heidegger, as is well known. Now according to Rorty, Kant 'gave us a history of our subject', an achievement without which, 'Greek thought and seventeenth century thought might have seemed as distinct both from each other and from our present concerns, as, say, Hindu theology and Mayan numerology' (Rorty 1979: 149). But if seventeenth century 
concerns were projected back to the Greeks, it is not clear why the same could not now be done for figures like Confucius and Nāgārjuna, especially given that non-Western thinkers have exerted an influence on Western philosophy ever since the seventeenth century, and are by now indisputably part of the conversation.

Given that non-Western thinkers could easily be included in Rorty's 'genealogical linkage', his reason for rejecting such an expansion must be prescriptive: he does not think the genealogy should be expanded, because, in accordance with his pragmatist convictions, he does not think this would be useful. The main reason Rorty gives for why it would not be useful, is that Western philosophers do not know what social needs non-Western thinkers were responding to. The needs of the ancient Greeks seem equally remote, of course, but Rorty thinks we can, 'with a fairly clear conscience', impose 'the grid of our own needs upon the books these men wrote', while 'blanking out most of their needs' (Rorty 1989: 332-3). This is because we are more 'mature' than our European ancestors, making it safe to assume that the elements of their thought now lost to us are 'no longer worth thinking'. Recapturing just an element of what they thought, however, allows us to 'sketch a dramatic narrative leading up to ourselves - the story of the modern mind (...) something which developed from infancy to adulthood' (ibid.). When we try to do this with non-Western intellectuals, however, 'we are never quite sure that we are not trying to make the adult answer the child's questions'. We share the 'the same human condition', but although this basic commonality allows us to communicate at a practical level, when we are 'trying to exchange ideas with the learned rather than commodities with the vulgar, our interlocutors' purposes may remain as obscure to us as ours to them'. In short, 'may not know what the other is saying these funnysounding things for' (ibid.: 333-5). 
The problem with bringing non-Western thinkers into the philosophical conversation, then, is that fruitful dialogue requires shared needs, but philosophy is a literature which arose from needs culturally specific to Western intellectuals. Since we do not know what needs gave rise to non-Western texts, and cannot 'leap out of our linguistic skin into the author's', these texts will inevitably remain full of 'sentences we cannot see the point of uttering' (ibid.: 337). The obvious rejoinder to this reasoning is that we need to learn about the needs that gave rise to non-Western texts, by studying the relevant intellectual histories, in order to determine whether philosophy really is culturally specific, or whether the needs which gave rise to some non-Western texts coincide sufficiently with our own to make fruitful dialogue possible. For though we must of course grant to Rorty that the 'sequence of intellectual history was very different in the various parts of Asia' (ibid.: 333), conditions may nevertheless have arisen that were similar enough to those prevalent in the West to produce texts worthy of comparison; this is surely not something we could rule out a priori.

Rorty does want to rule it out however, by leaning heavily on his ethnocentrism. Even when we read past Western philosophers, he says, we can never, for purely practical reasons, read enough of the books they themselves read, or learn enough about their social milieu, to fully understand the needs that motivated their writings. However, since they belong to our own (speaking from a Western perspective) intellectual heritage, we are entitled to impose our needs on their writings because they represent an earlier stage of our own thinking. To take an analogy: an adult who keeps a diary may no longer be able to fully understand some of the entries they made as a child, but if they find something that still seems relevant, they need not worry about fundamentally misinterpreting the text, because the text records earlier stages of their own intellectual development, over which they have a certain interpretative authority. This seems to be how Rorty is thinking about the place of past texts in Western thought as a 
whole. Since non-Western texts are not constitutive of the intellectual development of the West, then, and we can never learn enough to fully understand them, just as with Western texts, we cannot impose our own needs on them without risking fundamental misinterpretation; we can do it, but it would just be a 'feat of imaginative recontextualization' (ibid.:337) telling us more about ourselves than what the author had in mind.

For a philosopher who spent much of his career championing Derrida, this line of argument shows a staggering amount of respect for authorial intention. Rorty ended Philosophy and the Mirror of Nature with the hope that new ways of reading the classic texts of Western philosophy would be developed, free of the representationalist concerns that motivated their authors (Rorty 1979: 394), while in Contingency, Irony, and Solidarity, he enthusiastically endorsed Derrida's radical reinterpretations of Platonic texts as private, sexual fantasies (Rorty 1989a: chapter 6). In these moods, at least, Rorty's attitude to textual interpretation is simple: we can interpret a text any way we like if the interpretation serves our purposes. But if there is 'nothing behind the text', then surely there is 'nothing' whatever cultural background it comes from: if we can put a foreign text to good use for our own purposes, it is hard to see how Rorty, the pragmatist and enthusiast for radical re-readings, could possibly object. Moreover, Rorty once explicitly distinguished between three different ways of interpreting philosophical texts, all useful for different purposes, namely rational reconstruction, historical reconstruction, and Geistesgeschichte (Rorty 1998). ${ }^{6}$ Rational reconstruction involves philosophers imposing their own problems on past thinkers without concern for past intellectual contexts, historical reconstruction involves trying to understand past intellectual contexts, while Geistesgeschichte develops novel canons of great philosophers. Why should it be, then, that when Rorty turns his attention to non-Western philosophy, he suddenly seems to be exclusively concerned with historical reconstruction? 
When engaged in rational reconstruction and Geistesgeschichte, we know the authors were not addressing our needs, or are at least indifferent to whether they were or not, so why should it matter what cultural background they come from?

Rorty's case against comparative philosophy, then, is out of kilter with the general tenor of his thought, but even if we consider it in isolation, it is still unconvincing. Whatever force it has derives from tacitly treating Western thought as if it were some unified entity, 'the modern [Western] mind' (Rorty 1989: 332-3), that the great texts of Western philosophy and the minds of contemporary Westerners are all somehow part of. In reality, however, there are only people growing up and reading certain books, and which books they read, rather than the contemporary culture they read them in, is the overwhelmingly most important factor in determining which books they have most insight into. The idea that I have some special affinity, simply in virtue of being a twenty-first century English rather than Chinese person, with the needs which led Kant to write the Critique of Pure Reason or Plato the Republic, strikes me as patently absurd; affinities with traditions of thought are personal discoveries rather than cultural birth-rights. There are great cultural differences between contemporary China and England, of course, and some of these may in part be due to the historical influence of texts like the Republic and the Daodejing, but there is no reason to think growing up in a culture influenced by a text should provide privileged access to its meaning. Where you grow up does determine which books you are most likely to read, of course, but there is no ephemeral barrier preventing Western and non-Western scholars from sharing their differential expertise: if Western scholars get the wrong idea about what a non-Western writer 'is saying these funny-sounding things for', non-Western scholars can put them right. 
Another tactic Rorty employs, equally out of character and independently unconvincing, is to argue that comparative philosophy is untenable because Western and non-Western thinkers employ incommensurable conceptual schemes. This is a surprising tactic for Rorty, given that he endorsed Davidson's argument against drawing a scheme / content distinction ${ }^{7}$, and used it as a central plank of his case against Western philosophy: without this distinction, he had argued, philosophy could no longer purport to determine the representational adequacy of the conceptual scheme of human language to the intrinsic nature of the world (Rorty 1979: chapter 6). In the context of comparative philosophy, however, Rorty says that 'Davidson's argument holds only for whole languages, not for specialized jargons' (Rorty 1989: 336), and relies on this exception to claim that '[e]verybody who has ever compared a Western with a non-Western writer has done so by reference to a conceptual scheme, drawn up to reflect his or her particular purposes' (ibid.: 334). This allows Rorty to strengthen his previous conclusion that we can only justifiably impose our own purposes on thinkers from our own cultural tradition, and that if we impose them on a thinker from another tradition, who was likely to have been responding to very different needs, then we are likely to misinterpret them. For if the conceptual schemes of Western and non-Western thinkers do indeed serve different purposes, and hence are incommensurable, since commensurability requires commonality of purpose, then the idea of a cross-cultural comparison of different approaches to the same philosophical problems is misconceived. This is because the comparison could not provide either party with the means to solve their own philosophical problems, since philosophical problems are specific to a conceptual scheme and cannot be translated into an incommensurable one, and although each side could in principle learn the jargon of the 
other's conceptual scheme, the effort would be wasted because the jargon would only serve the other side's purposes, not their own.

This appeal to conceptual schemes is unsustainable within Rorty's thought as a whole, since a conceptual scheme needs unconceptualised content to organise, and Rorty's trademark claim that 'there is no one Way the World Is' (Rorty 1999: 33) requires that there is no such thing. It also partially undermines his critique of Western philosophy, because if there is indeed unconceptualised content, philosophy as a discipline which determines the representational accuracy of our conceptualisations again seems possible; restricting conceptual schemes to 'specialized jargons' is no help, since the original aim of philosophy, according to Rorty, was to show the accuracy of scientific language, not everyday discourse ${ }^{8}$ But even if we allow Rorty his appeal to conceptual schemes, they do not help his case. He tells us that 'philosophizing' may have ‘wildly different purposes at different times and places' (Rorty 1989: 337), with the implication that trying to appropriate another philosopher's ideas is almost bound to involve a misinterpretation of an incommensurable conceptual scheme addressed to different needs. But the problem with this reasoning is that if the other philosopher's ideas can readily be addressed to our purposes, without overly contorting their words in such a way as to attract the criticism of experts on that philosopher, then it is hard to see what would lead us to suspect incommensurability; the ability to enact a plausible application of another's ideas to our own problems, as routinely occurs in comparative philosophy, seems like the best possible evidence for commensurability.

Was Rorty trying to motivate a general scepticism about bringing philosophical ideas together, on the grounds that philosophical texts are addressed to too many different purposes for common ground ever to be found? This seems to be the direction the argument is heading, 
though it seems unlikely Rorty intended this outcome, given that it would undermine large swathes of his own work, which was particularly dependent on 'bricolage'. ${ }^{9}$ But even if this was the intention, the existence of so many successful syntheses of ideas throughout the history of philosophy suggests that if the purposes these ideas addressed really were as divergent as Rorty thinks, then the possibility of fruitful dialogue between philosophical ideas cannot have much to do with shared purposes. And here we come to the heart of the matter: given that so much non-Western writing is manifestly concerned with the nature of mind, time, knowledge, and other paradigmatic concerns of Western philosophy, then if philosophical writing does always relate to a purpose, whether social or private, this overlapping of topics seems to indicate a corresponding overlapping of purposes. If, however, this is held to be too unlikely, given the differences between the cultures in which the texts were written, then this seems to indicate that philosophical inquiry has considerably less to do with purposes than Rorty thinks it does.

Rorty's tactic of trying to undermine comparative philosophy by appealing to differing underlying purposes, then, is itself undermined by the manifest evidence that thinkers from different traditions have addressed the same topics; this suggests either that their purposes were similar, or else that purposes are largely irrelevant to commonality of philosophical inquiry. In his only explicit concession to this evidence, Rorty tried a different tactic, by suggesting that the reason we are apparently able to find recognisably philosophical writing within different cultures, is that there is 'a certain specific human type which can be counted upon to appear in any culture', namely what Nietzsche called 'the ascetic priest', somebody who tries to transcend to particularities of the culture they find themselves in by theorising about an underlying essence of reality; the goal of the 'ascetic priest', Rorty says, is 'always the ineffable' (Rorty 1991: 71). The danger of comparative philosophy, then, is the possibility 
that 'we are really comparing nothing more than the adaptations of a single transcultural character type to different environments' (ibid.).

The rather obvious flaw to this tactic, from Rorty's perspective, is that if philosophy is produced by a type of 'transcultural character', then since he grants that people with this character have similar needs, fruitful dialogue between philosophy from different cultures must be possible after all. Rorty might have argued that the ideas of such people are nevertheless not useful to society, but in fact he does not: he says that 'ascetic priests' have been 'the traditional vehicles of linguistic novelty' and hence are 'very useful people' (ibid.: 72-3); they may even be 'indispensible to culture' (Balslev 1991: 45). But in that case, intercultural exchange between, and comparison of, the ideas these people wrote about sounds as if it would be entirely worthwhile, even if, as Rorty also thinks, the ideas of 'ascetic priests' are little use in combating 'cruelty and injustice' (ibid.). ${ }^{10}$ The more fundamental problem, however, is that if there can be transcultural characters, there seems no reason why there should not also be transcultural problems. The evidence which leads to the hypothesis of transcultural characters is that people from different cultures wrote about similar topics, but in that case, the further hypothesis of a transcultural character-type to explain this similarity is redundant: the similarities between texts can be explained in terms of the topics addressed, which, barring some massive coincidence, we must presume to be transcultural. This explanation is not only simpler but considerably more plausible, given that we already know that many topics, such as mathematics and astronomy, are transcultural, while empirical psychological research has catalogued scores of reasons to regard human character-traits as largely a product of environment (c.f. Doris 2005). 
We have now considered all the reasons Rorty gave for his scepticism about the value of comparative philosophy, and discounted them. Given that these reasons seemed inconsistent with more characteristic elements of his thought, the question naturally arises: why was Rorty prepared to resort to such desperate measures to disparage comparative philosophy? Why did the prospect of non-Western philosophy make him suddenly lose his taste for 'imaginative recontextualization' (Rorty 1989: 337)? One answer, which on the face of it seems quite reasonable, is that Rorty believed that traditional Western philosophy was a socially counterproductive discourse. As such he wanted to spare non-Western cultures of its influence, and also wanted to avoid any prospect of Western philosophy renewing itself by absorbing new texts and thinkers, which he thought it would inevitably remould in line with its own counterproductive preoccupations; he worried that professional philosophers would apply Western philosophical categories to non-Western texts 'whether they are of any use or not' (Balslev 1991: 68). Given the validity of Rorty's critique of Western philosophy, then, it seems that he had good reason to try to undermine efforts to bring non-Western thought into dialogue with Western philosophy, even if his efforts were ultimately neither consistent nor successful.

However the underlying reason Rorty took up this combative stance on comparative philosophy, I want to suggest, is that the existence of non-Western philosophy undermines his critique of Western philosophy. For if non-Western philosophy exists, then Rorty's cultural specificity thesis is false, and so he can no longer claim that philosophical problems are rooted in obsolete European social issues, thereby casting doubt on the wisdom of continuing to try to solve them. Rorty might still have good arguments against representationalism or foundationalism, for instance, but without the cultural specificity thesis, these would simply count as arguments against certain approaches to answering 
questions about how the mind relates to the world, or about the nature of knowledge, whereas the conclusion Rorty wanted to establish was these questions are not worth pursuing at all, since they related only to an obsolete and culturally specific agenda. Since this conclusion was the most distinctive feature of Rorty's pragmatism, as he often emphasised (e.g. Rorty 1982c, Rorty 1990, Balslev 1991: 95), and remained central to his thought throughout his career, it is hardly surprising that he should have felt the need to persuade himself that nonWestern texts were probably not dealing with the same issues as Western ones, appearances to the contrary. ${ }^{11}$

IV

If philosophy is not the outgrowth of obsolete theoretical attempts to meet obsolete European needs, as Rorty believed, then what is it? Confronted with this question, philosophers have often felt inclined to give unhelpful answers, such as Russell's answer that the question is itself philosophical (Russell 1959: 7), Moore's answer that philosophy was the topic of the books on his bookshelves (Flew 1979: vii), or simply the more generic, po-faced answer that philosophy has been many things at many different times and places. These answers are unhelpful, of course, because we are not told the answer to Russell's question, or how he knew it was philosophical, and neither are we told the subject-matter of Moore's books, or what, if anything, the various historical discourses that have been called 'philosophical' had in common. Rorty, by contrast, does at least have a substantive, non-obfuscatory answer to offer, but one which the widespread evidence of non-Western philosophy renders doubtful. But if philosophy is not a culturally specific literary tradition, then what exactly are we recognising when we recognise philosophy within another culture? 
There is a sense in which the answer is obvious. Clearly it is not methodology, since so many different philosophical methodologies have been employed in philosophy. It might be suggested that philosophical inquiry is always a priori, but this is evidently not sufficient to capture what is distinctive about philosophy, since nobody would mistake ancient a priori speculations about meteorology, astronomy or anatomy, for instance, for works of philosophy. And in any case, the various methodologies employed within philosophy have in recent years been supplemented with empirical techniques (see Knobe and Nichols 2008), so it would now be hard to maintain that a priori methodology is even so much as necessary. Rather, what allows us to recognise philosophy is surely just subject-matter: philosophers talk about topics such as the ultimate structure of reality, the nature of mind and time, the possibility and scope of human knowledge, how to characterise the morally good life or the just society, and so on. We recognise philosophers in other cultures because we find them theorising about these kinds of topics; we see enough similarity in subject-matter between the writings of Xuan-zang and Leibniz, or Candrakīti and Locke, for instance, that we are left in little doubt about the existence of non-Western philosophy. This is no more surprising than that when Westerners discover non-Western intellectuals independently theorising about the internal angles of plane figures, for instance, then they are left in little doubt that geometry is more than just a Western pursuit.

Rorty refuses to avail himself of this obvious answer, and instead argues that any apparent commonality of subject-matter between Western and non-Western intellectuals is probably misleading; we are probably just reading our own interests into texts which contain an alien, inscrutable meaning, he suggests. This line of argument is not much more convincing than if someone were to argue that ancient Indian geometrical theories were probably not really about triangles and rectangles, all appearances to the contrary. Rorty talked himself into 
arguing this way because the obvious answer jarred with his commitment, pivotal to his critique of philosophy, to an historicist rejection of the view that philosophy deals with 'perennial, eternal problems - problems which arise as soon as one reflects' (Rorty 1979: 3). But if we look more dispassionately at the evidence for philosophy in cultures that were not influenced by the Greeks, as comparative philosophers have always tried to do, it looks eminently plausible that philosophy does indeed deal with 'perennial, eternal problems', at least in so far as problems in geometry, astronomy or meteorology might also be described this way, i.e. as matters in need of reflection and explanation that are more or less bound to occur to people, irrespective of their cultural and historical background. The suggestion I would like to end with, then, is that just like geometry, astronomy and meteorology, philosophy has a natural subject-matter. ${ }^{12}$

Now the obvious answer that philosophy is united by a distinctive subject-matter, is itself fairly unhelpful so long as we do nothing more than list some paradigmatic topics without saying what they have in common; in doing this, we are simply relying upon our familiarity with the subject-matter of philosophy, without providing any insight into its unity. Of course it would be naïve to suppose that all philosophy has one thing in common, given its long and complex history; such a historically and geographically diverse cultural phenomenon is bound to rather consist in 'a complicated network of similarities overlapping and crisscrossing' (Wittgenstein 1953: 32), a network open-ended enough to embrace atypical subjectmatters, such as the philosophy of sport or wine, for instance (cf. McGinn 2008, Smith 2007). However this concession is perfectly compatible with claiming that the network has developed, in complicated and diverse ways, from certain prototypical and natural concerns, rather as similarly complex networks have developed from prototypical and natural concerns with angles and shapes, the stars, and the weather. Such basic concerns provide gravitational 
centres that bind areas of inquiry together, and there is no good reason to think that philosophy should lack its own. Moreover we do not have to look far to remember what they are, for although they are concerns which have become peripheral to most contemporary debates, they retain an ineluctable association with the discipline, especially in the public consciousness. The concerns I am alluding to are the meaning of life and transcendence.

No matter what our cultural background, we all find ourselves thrown into the thick of life with the question of what to do with that life potentially unsettled; new people are born every day who may one day break free of the presupposed meaning provided by their upbringing, and find themselves existing, caught up in a time that carries them to death, and capable of steering their lives in different directions. In such conditions, it is natural for some curious, reflective types, to ask themselves what they are supposed to be doing with their lives. Asking this question has led thinkers from various cultures into hypotheses of transcendence: perhaps, the thought begins, the purpose of human life as a whole is determined on a higher plane of existence, a greater context into which the comparatively petty affairs of mankind can be placed. This idea, to be found within ancient philosophical and religious thought around the world, is unsurprising given that one of our standard patterns of explanation involves invoking a wider context of meaning into which a phenomenon can be placed. Thus if we encounter somebody systematically moving their arms, for instance, we instinctively seek to explain this behaviour by placing it into a social context which makes its purpose manifest. In trying to understand human life as a whole, then, it is only to be expected that we should have sought to employ the same form of teleological explanation that usually serves us so well within the social context provided by human life, and that in trying to use this pattern of explanation to encapsulate human life as a whole, we should have felt the need to look beyond the human context to hypotheses of transcendence. 
Many religions have hypothesised transcendent contexts of meaning supplied by supernatural gods, which can then be appealed to in answering practical concerns about how we ought to act. Philosophy has often followed a similar path, but is distinctive in its exploration of the possibility of various rational routes to the hypothesis of transcendence, and its subsequent concern to critically delineate the metaphysical, epistemological and ethical consequences of such hypotheses. Thus in ancient Greece, Parmenides argued that the concept of nonexistence must be purged from our understanding to generate a new and more adequate understanding of reality as timeless and unchanging. The implication of this argument was that the changing world we observe is merely apparent and that reality transcends perception and can be apprehended only by reason. Similarly, in ancient China, Laozi argued that the unitary and undifferentiated reality of Dao transcends perception, although he adopted the rather more paradoxical stance that the reality of Dao could not be apprehended by reason due to the inadequacy of human language; this kind of ineffability thesis is to be found in most of the major philosophical traditions, as for instance in the Lañkāvatāra Sūtra, and in Neo-Platonists from Plotinus to Damascius. And similarly, in ancient India, Buddhist thought developed the idea that true reality transcends the perceived world, which is to be understood as a kind of delusion we must learn to free ourselves from in order to achieve enlightenment.

In all these independent philosophical traditions, hypotheses of transcendence yield implications for the meaning of life. Thus Plato, whose rational route to transcendence was that in order to account for the generality of conceptual thought the particular objects and events we perceive must be transcended by a reality of universals, holds that the philosopher kings' knowledge of transcendent reality will allow them to know how we ought to live, and he also uses his metaphysics of transcendent universals to explain 'why the creator made this 
world of generation' (Timaeus 29d-e / Plato 1961: 1162). And similarly, many ancient nonWestern philosophies have also held that thinking beyond the perceptual world provides guidance in understanding the purpose of our lives; thus for Laozi, conformity to the Dao, which is hidden from perception, provides moral guidance by inculcating otherwise overlooked virtues such as inactivity, while Buddhist thought teaches us to detach ourselves from the illusory world of perception in order to achieve tranquillity and salvation.

At the beginning of some of the most influential traditions of philosophical thought, then, we find natural curiosity about the purpose of our lives, and our practical need to decide what to do with them, met by thinking beyond our ordinary, perception-based conception of the world, and thus by rethinking reality with the concept of transcendence. Once we do this, however, a familiar subject-matter immediately opens up. Epistemological questions arise concerning the relation between potentially illusory appearance and transcendent reality - or the relation between dharmas and the Dharma - and metaphysical questions arise concerning the ultimate status of appearance and reality. Thus on the epistemological side, we begin to ask ourselves what it is possible for us to know, given that reality transcends perception; as Rorty rightly points out, Western philosophy, under the influence of Plato, was to become dominated by this agenda once it had been interpreted as the task of determining the conditions of accurate representation. But contra Rorty (esp. Rorty 1979: chapter 3), this agenda cannot plausibly, given the evidence of non-Western philosophy, be equated with philosophical inquiry itself; it was simply one important direction, taken within one important tradition, in the pursuit of a much wider agenda. For equally important to that wider agenda have been metaphysical questions, which within both Eastern and Western traditions have tended to centre on questions about the nature of mind, as well as the teleological and ethical questions to which epistemological and metaphysical inquiries have so often been directed. 
To claim that the core subject-matter of philosophy centres on prototypical concerns about the meaning of life and transcendence is not to deny that these concerns have in many cases been left behind. Thus, for example, Platonic realism about universals remains a live theory, but its contemporary incarnations (e.g. Armstrong 1980) have little to do with Plato's metaphysics of transcendence, and even less to do with his humanistic concerns. In fact, Western philosophy in the last century was, arguably, in large part characterised by a systematic attempt to eradicate notions of transcendence and a univocal meaning of life, whether through naturalism in analytic philosophy, or existentialism and deconstruction in continental philosophy. But this is no objection to the naturalness of philosophy, since mature disciplines typically leave behind the natural concerns that gave them their start, and often react against their founding assumptions. Of course, the rootedness of the subject-matter of philosophy in unfashionably aprioristic and unscientific notions such as transcendence, might be thought to indicate something fundamentally awry with it. Moreover, the remedy might be thought to lie with a purely 'therapeutic rather than constructive' (Rorty op. cit: 7) approach to philosophy, of a kind which was arguably to be found within Eastern philosophy long before the likes of Wittgenstein and Rorty (cf. Read 2009). But whether there is anything wrong with philosophical thought or not, it seems abundantly clear there is nothing culturally specific about it. As such, Rorty's famous historicist critique falls at the first hurdle. 


\section{References}

Armstrong, D. (1980) A Theory of Universals: Universals and Scientific Realism, volume II, Cambridge: Cambridge University Press.

Balslev, A. (1991) Cultural Otherness: Correspondence with Richard Rorty, Atlanta, GA: Scholars Press.

Clarke, J.J. (1997) Oriental Enlightenment: The Encounter between Asian and Western Thought, London: Routledge.

Dewey, J. (1917) Creative Intelligence: Essays in the Pragmatic Attitude, New York: Henry Holt.

Doris, J. (2002) Lack of Character: Personality and Moral Behaviour, Cambridge: Cambridge University Press.

Flew, A. (1979) A Dictionary of Philosophy, London: Macmillan.

Froese, K. (2004) 'From Nihilism to Nothingness: A Comparison of Nietzschean and Daoist Thought', Dao: A Journal of Comparative Philosophy, 4: 97-116.

Gopnik, A. (2009) 'Could David Hume Have Known About Buddhism? Charles Francoise Dolu, the Royal College of La Flèche, and the Global Jesuit Intellectual Network', Hume Studies, 35: 5-28.

Guignon, C. (1986) 'On Saving Heidegger from Rorty', Philosophy and Phenomenological Thought, 46: 401-417.

Jacobson, N. (1969) ‘The Possibility of Oriental Influence in Hume’s Philosophy', Philosophy East and West, 19: 17-31.

Knobe, J. (1995) 'A Talent for Bricolage: An Interview with Richard Rorty', The Dualist, 2: $56-71$.

Knobe, J. and Nichols, S. (eds.) (2008) Experimental Philosophy, Oxford: Oxford University Press. 
Macdonald, P. (2003) History of the Concept of Mind, Aldershot, UK: Ashgate.

Matson, W. (1966) 'Why Isn’t the Mind-Body Problem Ancient?’ in P. Feyerabend and G. Maxwell (eds.) Mind, Matter and Method: Essays in Philosophy and Science in Honor of Herbert Feigl, Minneapolis: University of Minnesota Press.

McGinn, C. (2008) Sport, Durham, UK: Acumen Press.

Plato (1961) The Collected Dialogues of Plato, eds. E. Hamilton and H. Cairns, trans. L. Cooper, Princeton: Princeton University Press.

Read, R. (2009) 'Wittgenstein and Zen Buddhism: One Practice, No Dogma', in M.

D’Amato, J. Garfield and T. Tillemans (eds.) Pointing at the Moon: Buddhism, Logic, Analytic Philosophy, Oxford: Oxford University Press.

Rorty, R. (1979) Philosophy and the Mirror of Nature, Princeton: Princeton University Press.

Rorty, R. (1982a) 'Philosophy as a Kind of Writing: An Essay on Derrida', in his Consequences of Pragmatism. Minneapolis: University of Minnesota Press.

Rorty, R. (1982b) 'The World Well Lost', in his Consequences of Pragmatism. Minneapolis: University of Minnesota Press.

Rorty, R. (1982c) 'Pragmatism, Relativism, and Irrationalism', in his Consequences of Pragmatism. Minneapolis: University of Minnesota Press.

Rorty, R. (1989) 'Review of Interpreting Across Boundaries: New Essays in Comparative Philosophy, edited by Gerald James Larson and Eliot Deutsch', Philosophy East and West, 39: 332-7.

Rorty, R. (1989a) Contingency, Irony, and Solidarity, Cambridge: Cambridge University Press.

Rorty, R. (1990) 'Introduction: Pragmatism as Anti-Representationalism', in J. Murphy, Pragmatism: From Peirce to Davidson, Boulder, CO: Westview. 
Rorty, R. (1991) 'Heidegger, Kundera, and Dickens', in his Essays on Heidegger and Others: Philosophical Papers, vol. 2, Cambridge: Cambridge University Press.

Rorty, R. (1998) 'The Historiography of Philosophy: Four Genres', in his Truth and Progress: Philosophical Papers, vol. 3, Cambridge: Cambridge University Press.

Rorty, R. (1999) Philosophy and Social Hope, London: Penguin.

Rorty, R. (2000) 'Response to Williams', in R. Brandom (ed.) Rorty and His Critics, Oxford: Blackwell.

Russell, B. (1959) Wisdom of the West: A historical survey of Western philosophy in its social and political setting, Garden City, NY: Doubleday.

Smith, B. (ed.) (2007) Questions of Taste: The Philosophy of Wine, Oxford: Oxford University Press.

Staal, F. (1988) 'Is There Philosophy in Asia?', in G. Larson and E. Deutsch (eds.) Interpreting Across Boundaries: New Essays in Comparative Philosophy, Princeton: Princeton University Press.

Steffney, J. (1977) ‘Transmetaphysical Thinking in Heidegger and Zen Buddhism’, Philosophy East and West, 27: 323-35.

Williams, M. (2000) 'Epistemology and the Mirror of Nature', in R. Brandom (ed.) Rorty and his Critics, Oxford: Blackwell.

Wittgenstein, L. (1953) Philosophical Investigations, trans. G.E.M. Anscombe, Oxford: Blackwell.

Zhang, W. (2006) Heidegger, Rorty, and the Eastern Thinkers: A Hermeneutics of CrossCultural Understanding, New York: State University of New York Press. 
${ }^{1}$ Although Rorty later distanced himself from the term 'hermeneutics', the reason was mainly to distance himself from Gadamer; see [DELETED]. Rorty's commitment to edification through the creation of and interaction with unfamiliar discourses, however, remained just as strong; it is central to his later conceptions of the 'liberal ironist' and 'strong poet', for instance (Rorty 1989a).

${ }^{2}$ To take just two examples that might have appealed to Rorty, John Steffney has argued that there is a residue of dualistic thinking in Heidegger's later thought which is absent from the Chan Buddhist thinking with which it otherwise bears close comparison (Steffney 1977), while Katrin Froese has argued that the morally negative connotations of nothingness found in Nietzsche's conception of nihilism are avoided in Daoist philosophy (Froese 2004).

${ }^{3}$ Rorty is referring to the title of a paper by Frits Staal: although the title evidently appealed to Rorty, Staal argues that 'there is such a thing as philosophy in India' (Staal 1988: 214), and is generally dismissive of any attempt to 'define philosophy in terms of the legacy of the Greeks' (ibid.: 204), which is effectively what Rorty does.

${ }^{4}$ I have dealt with the other main problem, the fact that Rorty's case against philosophy relies on philosophical arguments, in [DELETED].

${ }^{5}$ Wei Zhang (Zhang 2006: 29-31) detects a shift in Rorty's position, with his essentialist commitment on the nature of philosophy only appearing in the late ' $80 \mathrm{~s}$ in the context of nonWestern philosophy. It seems to me, however, that the commitment was there a decade earlier in Philosophy and the Mirror of Nature; Zhang is right that Rorty's notion of cultural criticism was anti-essentialist, but cultural criticism was Rorty's suggestion for a replacement for traditional philosophy, and was preceded by critique of philosophy that depends on characterising it, in accordance with the cultural specificity thesis, as essentially Eurocentric. 
${ }^{6}$ This essay was originally published in 1984 and Rorty chose to reprint it in 1998, so his brief consideration of non-Western philosophy in 1989-91 cannot have changed his mind; Rorty has no use for the fourth genre he discusses in that essay, namely 'doxography'. ${ }^{7}$ Originally in his 1972 paper 'The World Well Lost' (Rorty: 1982b), published two years before Davidson's 'On the Very Idea of a Conceptual Scheme'.

${ }^{8}$ From Rorty's perspective, it would be better to understand incommensurable discourses as simply different ways of talking about the world that are practically difficult to reconcile: different ways of talking not about the world-in-itself, but the world as we understand it in everyday discourse. This ill-judged appeal to conceptual schemes, however, highlights the tension that always existed between Rorty's endorsements of both Davidson's rejection of the scheme / content distinction, and Kuhn's model of scientific revolutions, which Kuhn himself understood in terms of changing conceptual schemes; see [DELETED].

${ }^{9}$ It is also worth noting that Rorty's emphasis here on the multiplicity of purposes philosophical texts can serve, seems to directly contradict the basis of his critique of Western philosophy, namely that the whole discipline is rooted in the same obsolete social needs. ${ }^{10}$ If 'ascetic priests' are specialists in metaphysical ideas, then this latter claim seems no more surprising than the fact theoretical physics is no use against 'cruelty and injustice'. ${ }^{11}$ This would not be the first time Rorty's neglect of a philosophical tradition invalidated one of his conclusions. In addition to what Michael Williams called Rorty's 'emergence' and 'projection' theses, Rorty also proposed a 'reversal' thesis, which is that modern philosophy reversed the dependence between metaphysics and epistemology. As Williams points out, however, Hellenistic philosophy already contained a notion of epistemology as prior to metaphysics (Williams 2000); Rorty conceded the point and abandoned the reversal thesis (Rorty 2000). The cultural specificity thesis was considerably more central to Rorty's project, however, and despite the criticism he received when trying to defend it in the context of non- 
Western philosophy, most notably from Anindita Balslev (Balslev 1991) and Wei Zhang (Zhang 2006), he never abandoned it.

${ }^{12}$ I have defended this claim in more detail in [DELETED] and will provide a full defence in [DELETED] 